\title{
The role of neurohormonal imbalances in obesity
}

\section{Introduction}

There are several theories available to elucidate the obesity epidemic that began in the period of 1976-1980 with a sudden upstroke in $1977 .{ }^{1}$ One may assume that the increased availability of cars and fast food might explain this upstroke by indirectly altering behavior resulting in the increased food intake and lack of exercise as a potential cause of this epidemic. Many researchers now believe hormonal imbalances to be the primary reason behind this epidemic and the mentioned behavior is only secondary to these hormonal imbalances. ${ }^{2}$ We discuss here about how the food we are eating can disrupt the hormones in our body. After this discussion, it would be appropriate to say that we are getting fat not because we are eating more, instead we are eating more because we are getting fat.

\section{Discussion}

Hunger and satiety are generally regulated by the central nervous system (CNS) via the gut-brain axis and a number of hormones play critical roles in body weight management. ${ }^{3,4}$ Among these hormones, the three most important hormones are leptin, ghrelin and insulin. ${ }^{5}$ Leptin is a hormone secreted by fat cells which sends negative feedback signals to the brain to stop eating (satiety hormone). ${ }^{6}$ Ghrelin is a hormone secreted by the stomach when it is empty and stimulates appetite by binding to the growth hormone secretagogue receptors (GHSRs) in the brain (hunger hormone)..$^{7-10}$ On the other hand, insulin is a hormone that signals the cells to take glucose from the bloodstream and store it as a glycogen or fat and just like leptin it signals brain to stop eating. The other action of insulin is to interfere with the signals sent to the brain by leptin (reduces leptin sensitivity) and this action can be considered as the major cause of obesity. ${ }^{11}$ People with chronically elevated insulin levels (hyperinsulinemia) thus become leptin resistant and start eating more as the brain cannot sense the signals sent by leptin which makes the brain to think that the body is still starving. Another action of insulin is to send signals to fat cells and stimulate them to store fat and keep fat stored for longer period. ${ }^{12}$ However, this action of insulin is debatable and many researchers do not agree with the existence of this action.

In obese individuals, leptin and ghrelin levels are expected to be low and high respectively, but in reality, they have high leptin and low ghrelin levels. ${ }^{13}$ In one study,${ }^{14}$ plasma leptin levels were measured in lean and severely obese women during a 12-hour fasting state (baseline) and a 2-hour postprandial state (measured at 0, 15, $30,60,90$ and 120min after ingestion of a body weight-adjusted test meal). The results showed significantly higher baseline leptin levels in the obese subjects which gradually decreased during the first $90 \mathrm{~min}$ of the postprandial state and abruptly thereafter. On the other hand, the leptin levels in the lean subjects remained relatively constant during the 2-hour postprandial period. ${ }^{4,14}$ Meanwhile, fasting and postprandial plasma ghrelin levels were reported to be lower in obese than in lean individuals in the same study. ${ }^{14}$ Additionally, another study showed higher baseline leptin levels in obese subjects compared to lean subjects. ${ }^{15}$ Furthermore, Yang et al., ${ }^{16}$ reported greater postprandial suppression of ghrelin in obese as well as lean subjects after a high carbohydrate meal rather than a high fat meal.
Volume 7 Issue I - 2017

\author{
Niel N Shah, Muhammad U Dogar and \\ Timothy JVittorio \\ St Francis Hospital, The Heart Center $®$, USA
}

Correspondence: Timothy J Vittorio, St Francis Hospital, The Heart Center $\AA$, Center for Advanced Cardiac Therapeutics, 100 Port Washington Blvd, Roslyn, NY I I576- I348, USA, Tel 5166292166, Fax 5166292094, Email t_vittorio@hotmail.com

Received: May 30, 2017| Published: June 27, 2017

However, obese individuals demonstrated less ghrelin suppression following either meal when compared to the lean subjects. The high leptin levels can be explained by the leptin resistance present in obese individuals, while the reason behind low ghrelin levels is unclear and whether high leptin causes the low levels of ghrelin is uncertain. It may be explained by the oversensitivity to ghrelin in such individuals due to over expression of the GHSRs. Furthermore, it seems that the leptin has no influence over ghrelin secretion. ${ }^{17}$

The major stimulus for insulin secretion from the pancreas is dietary carbohydrates. It has been shown in many studies that eating low simple carbohydrate food leads to a reduction in insulin levels and eventually weight loss. ${ }^{18-20}$ The carbohydrate dependent secretion of insulin from the pancreas is directly related to the amount of fat in the body. Therefore, people with high body fat content have high insulin levels. Moreover, there is a certain limit to the amount of insulin that can reach to the brain and stimulate satiety. When the amount of insulin exceeds this limit (hyperinsulinemia), then no further insulin can reach the brain and decrease the appetite, which is termed as insulin resistance. As previously discussed, hyperinsulinemia can also cause leptin resistance and thus hyperinsulinemia, leptin resistance and insulin resistance all are interrelated and can be considered as major causes of obesity. Meanwhile, we can consider reversal of hyperinsulinemia as one of the best way to fight against the obesity epidemic.

\section{Conclusion}

In summary, it is important to maintain a diet which consists of foods with a low glycemic index. The low glycemic load seems to result in homeostasis of the satiety and hunger hormones (leptin and gherlin). As a result, glucose levels remain lower and the characteristic rise in insulin is blunted. This is a safe way to obtain both weight loss and maintenance. The abdominal muscles that we all seek to reveal are really 'made in the kitchen'.

\section{Acknowledgements}

None.

\section{Conflict of interest}

The author declares no conflict of interest. 


\section{References}

1. Fryar CD, Carroll MD, Ogden CL. Prevalence of Overweight, Obesity, and Extreme Obesity among Adults: United States, 1960-1962 Through 2011-2012. USA: CDC; 2014.

2. Lustig RH. Childhood obesity: behavioural aberration or biochemical drive? Reinterpreting the First Law of Thermodynamics. Nat Clin Pract Endocrinol Metab. 2006;2(8):447-458.

3. Adamska E, Ostrowska L, Górska M, et al. The role of gastrointestinal hormones in the pathogenesis of obesity and type 2 diabetes. Prz Gastroenterol. 2014;9(2):69-76.

4. Lean ME, Malkova D. Altered gut and adipose tissue hormones in overweight and obese individuals: cause or consequence? Int $J$ Obes (Lond). 2016;40(4):622-632.

5. Cigdem Arica P, Kocael A, Tabak O, et al. Plasma ghrelin, leptin, and orexin-A levels and insulin resistance after laparoscopic gastric band applications in morbidly obese patients. Minerva Med. 2013;104(3):309316.

6. Brennan AM, Mantzoros CS. Drug Insight: the role of leptin in human physiology and pathophysiology - emerging clinical applications. Nat Clin Pract Endocrinol Metab. 2006;2(6):318-327.

7. Sakata I, Sakai T. Ghrelin cells in the gastrointestinal tract. International Journal of Peptides. 2010;2010:1-7.

8. Muller TD, Nogueiras R, Andermann ML, et al. Ghrelin. Mol Metab. 2015;4(6):437-460.

9. Dockray GJ. Gastrointestinal hormones and the dialogue between gut and brain. J Physiol. 2014;592(14):2927-2941.

10. Callaghan B, Furness JB. Novel and conventional receptors for ghrelin, desacylghrelin, and pharmacologically related compounds. Pharmacol Rev. 2014;66(4):984-1001.
11. Lustig RH, Sen S, Soberman JE, et al. Obesity, leptin resistance, and the effects of insulin reduction. Int $J$ Obes Relat Metab Disord. 2004;28(10):1344-1348.

12. Strålfors P, Honnor RC. Insulin-induced dephosphorylation of hormonesensitive lipase. Correlation with lipolysis and cAMP-dependent protein kinase activity. Eur J Biochem. 1989;182(2):379-385.

13. Tschöp M, Weyer C, Tataranni PA, et al. Circulating ghrelin levels are decreased in human obesity. Diabetes. 2001;50(4):707-709.

14. Carlson JJ, Turpin AA, Wiebke G, et al. Pre-and post-prandial appetite hormone levels in normal weight and severely obese women. Nutr Metab. 2009;6:1-32.

15. Carroll JF, Kaiser KA, Franks SF, et al. Influence of BMI and gender on postprandial hormone responses. Obesity (Silver Spring). 2007;15(12):2974-2983.

16. Yang N1, Liu X, Ding EL, et al. Impaired ghrelin response after highfat meals is associated with decreased satiety in obese and lean Chinese young adults. J Nutr. 2009;139(7):1286-1291.

17. Klok MD, Jakobsdottir S, Drent ML. The role of leptin and ghrelin in the regulation of food intake and body weight in humans: a review. Obes Re. 2007;8(1):21-34.

18. Hernandez TL, Sutherland JP, Wolfe P, et al. Lack of suppression of circulating free fatty acids and hypercholesterolemia during weight loss on a high-fat, low-carbohydrate diet. Am J Clin Nutr. 2010;91(3):578585 .

19. Boden G, Sargrad K, Homko C, et al. Effect of a low-carbohydrate diet on appetite, blood glucose levels, and insulin resistance in obese patients with type 2 diabetes. Ann Intern Med. 2005;142(6):403-411.

20. Noakes M, Foster PR, Keogh JB, et al. Comparison of isocaloric very low carbohydrate/high saturated fat and high carbohydrate/low saturated fat diets on body composition and cardiovascular risk. Nutr Metab (Lond). 2006;11:3-7. 